\title{
AN INNOVATIVE BUSINESS MODEL BASED ON THE INTEGRATION OF FINANCE AND LOGISTICS OPERATIONS
}

\author{
ZHAO DAOZHI ${ }^{1}$ \\ MAPENG BAI2 \\ CHARLES MBOHWA $3 *$ \\ 1dzzhao@tju.edu.cn \\ Logistics and Supply Chain Management Department, \\ School of Management, Tianjin University, China \\ 2baimapeng@gmail.com \\ Management Department, Tianjin T\&B International Logistics Co., Ltd., China \\ 33cmbohwa@uj.ac.za \\ *Corresponding Author, Department of Quality and Operations Management, \\ University of Johannesburg, South Africa
}

\begin{abstract}
This article advances a new logistics financing model based on the notes receivable. This is a written promise to receive a stated amount of money in future. The article describes the structure and key processes of the model, and analyses the roles of the involved stakeholders. In order to enhance understanding, the article compares the model with a loan financing model, establishes a game model based on logistics enterprise financing, studies the strategies in the process of investment and financing, and concludes by defining its feasible region. This involves comparing the expected net revenues of different stakeholders in the two models. Based on the results, the paper analyses the financing process of a logistics enterprise in Shanghai and determines the optimal financing strategy. This paper is an attempt to improve business innovation in logistics financing and provides a sensible solution for the integrated logistics and finance services. This can effectively improve the stakeholders' profit.
\end{abstract}

\section{INTRODUCTION}

There has been a recent development whereby many enterprises and logistics providers owe logistics service fees or use a deposit system to reduce operational costs. Small and medium-sized logistics enterprises (SMLEs), in an effort to expand the market and win orders, usually accept the harsh demands of customers resulting in a huge burden on the notes receivable. In China, small and medium enterprises in the transportation industry have revenues of up to 200 million Chinese yuan (renminbi) (US\$32 million) and a maximum of 300 employees (China Briefing, 2011). Powerful large-scale logistics enterprises can be in a better position during logistics services contract negotiation depending on management 
capabilities, strength of financial backing and their reputation. Large-scale enterprises have revenues exceeding 200 million Chinese yuan and many exceed 1 billion Chinese yuan (US\$160 million) (China Briefing, 2011). However the increasing competition often means that these companies face many problems, such as increased operational costs, reduced profit margins and customer defection. They therefore need to effectively integrate their management and capital advantages with the operational costs advantages of SMLEs to form a new logistics operation model. This has resulted in the fast-developing study area of logistics financing. In the process larger companies seek to improve the performance of service providers and suppliers through financial mechanisms without increasing the risks associated with ownership or part-ownership of the client SME.

Logistics financing is an operating process, which through applying and developing various financial products, can organise and regulate the monetary capital movement through the logistics chain more effectively. The capital movements include deposits, loans, investment, trusts, leasehold, mortgages, discounts, insurance, securities and middle services related to the logistics (Zou \& Tang, 2004). Reviewing the literature in the field (Feng, 2007), there are the following aspects to be studied: (1) The influence of financial constraints on enterprise behaviour (Buzacott \& Zhang, 2004); (2) Business mode analysis (Luo, Zhu \& Chen, 2002; Sun, 2004); (3) Credit contract design (Stiglitz \& Weiss, 1981); (4) The management and control of mortgage (Kuosmanen \& Post, 2003; Berger \& Udell, 2004; Liu, Zhao \& Cao, 2005); (5) Risk management research (Coulter and Onumah, 2002; Schwartz \& Smith, 2003). As a new logistics derivative service, logistics financing is continually innovating and evolving, from helping the consignor with an advance payment to the modern prevailing warehouse receipt pledging, financing warehouse, and bonded warehouse. This paper proposes a new logistics financing model based on notes receivables and establishes the necessary pre-conditions for it to be feasible, optimal and desirable.

\section{INTRODUCTION OF THE FINANCING MODEL}

The main body of the financing model is called the Notes Receivables Financing-Logistics Company (NRF-LC) Model. It consists of financial institutions (mainly commercial banks), large-scale logistics enterprises, financing logistics enterprises, and customers, including spin-offs. The relationship between stakeholders in the system is depicted in Figure 1. 
An Innovative Business Model Based on the Integration of

Finance and Logistics Operations

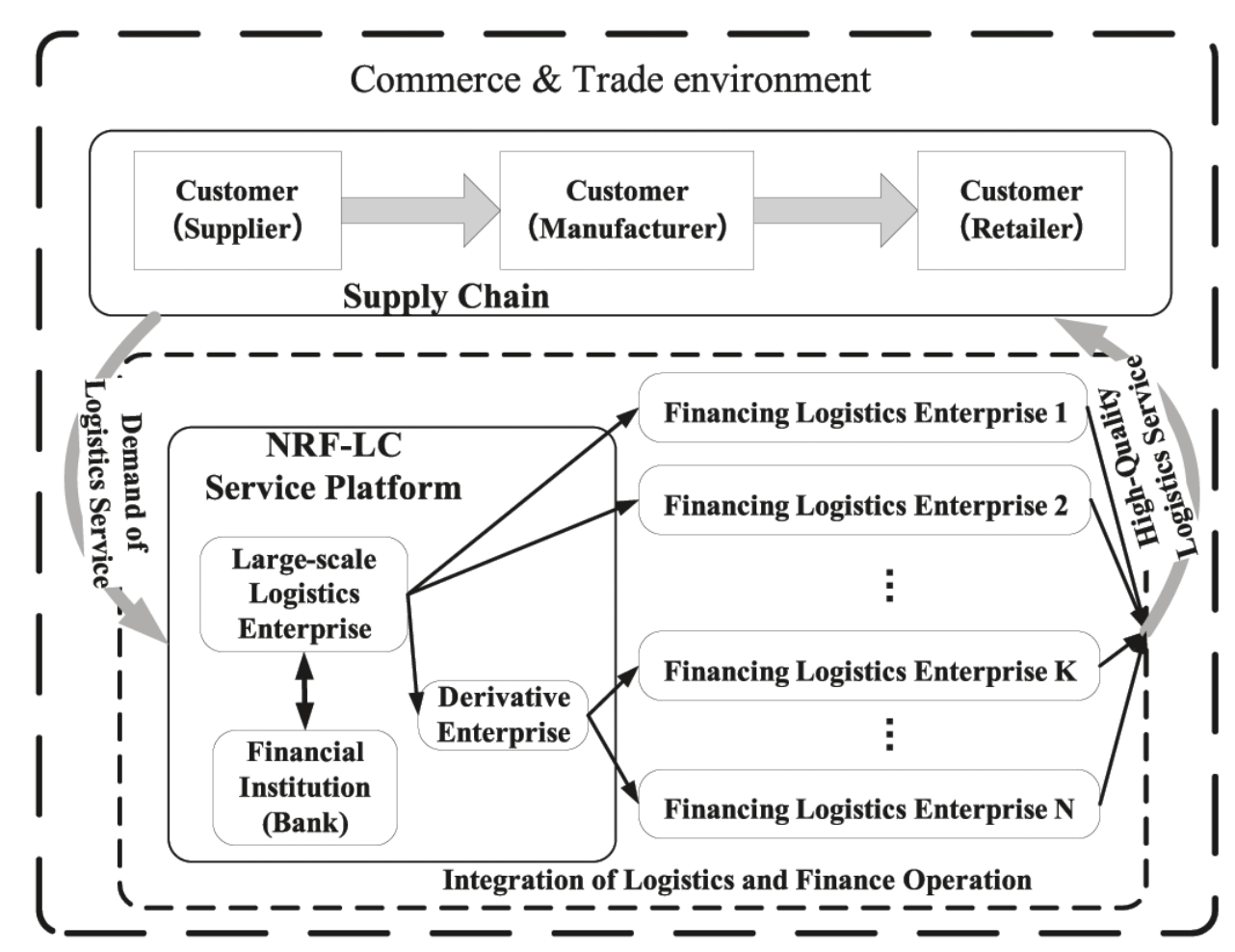

Figure 1: NRF-LC model structure

The operational processes of the financing service model consist of two parts which will be simply summarised as: logistics operations processes and capital operations processes. As a key link in the supply chain, the financing model service platform plays an important role as a logistics service supplier. In order to make the logistics service chain run more smoothly, there is a need to develop a series of routine management systems that make up the operations of relevant businesses. The detailed depiction of the logistics operations processes are shown in Figure 2.

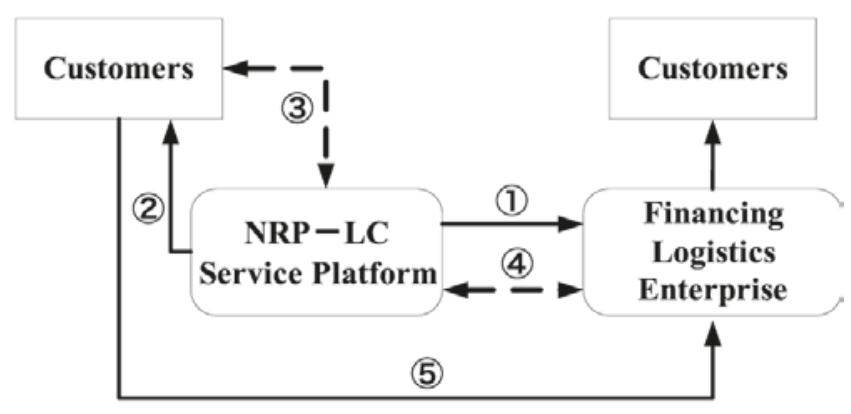

Figure 2: The logistics operation process (1 - information to large-scale enterprise; 2 - information to customer; 3 - feedback; 4 - feedback; 5 - Service provision and payment)

The different numerical characters in Figure 2 are defined as follows:

1 NRF-LC service platform evaluates the financing of logistics enterprises.

2 NRF-LC service platform selects and evaluates the customers.

3 NRF-LC service platform prescribes the logistics service contract for the target customers. 
4 NRF-LC service platform prescribes the logistics subcontracts for the financing of the logistics enterprises.

5 The logistics enterprises provide logistics services to the chosen customers.

The capital operation process mainly includes two parts: the prepaid accounts control process and settlement control process as shown in Figures 3 and 4 .

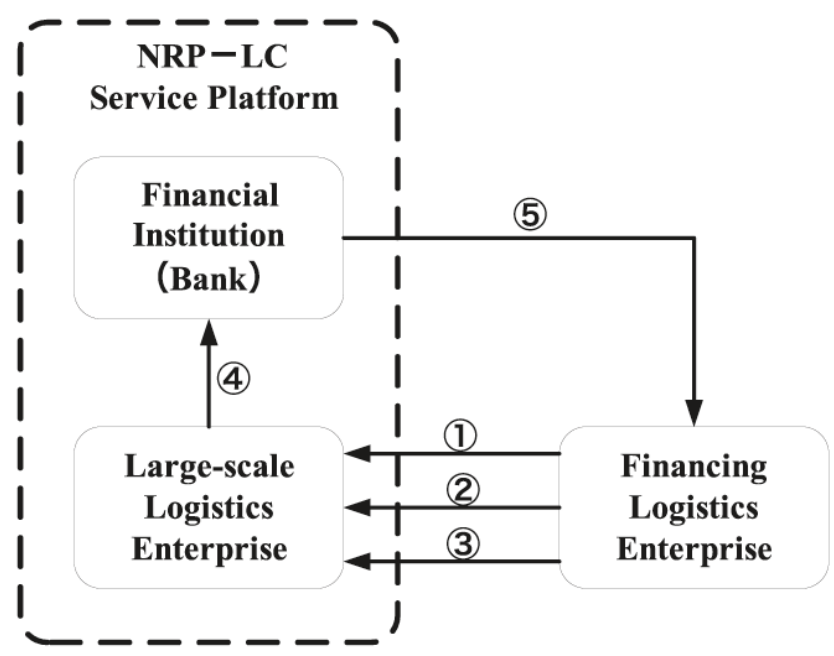

Figure 3: The prepaid accounts control process (1, 2 \& 3 - flows of budget information, deposit and settlement request; 4 - acceptance bills; 5 - service bill)

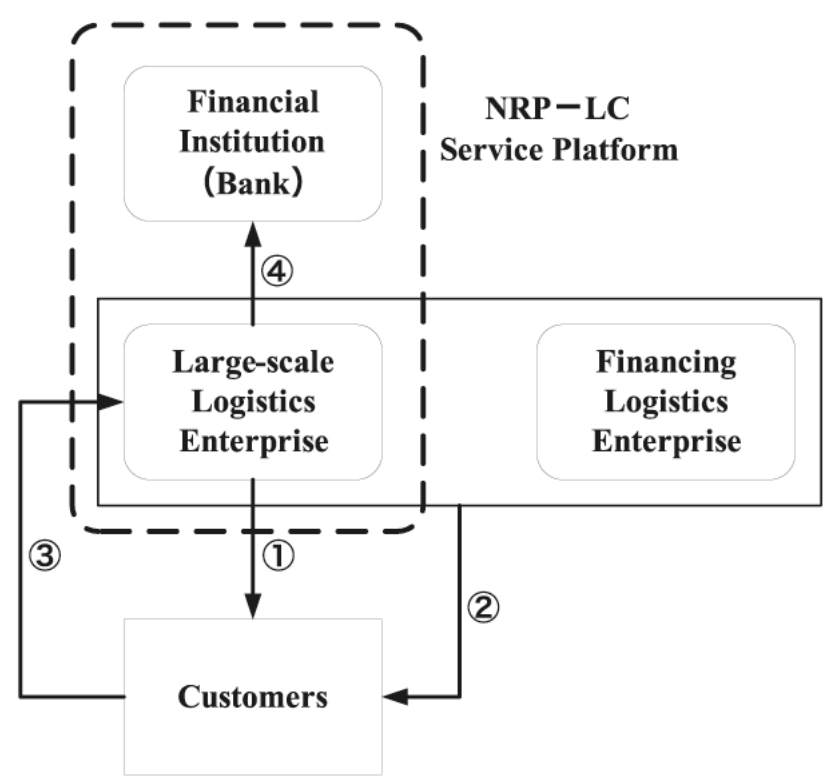

Figure 4: The settlement control process

The numeric characters in Figure 3 represent the following:

1 The financing logistics enterprise makes a budget relying on the forecast volume of business, and then submits it to the NRF-LC service platform for approval.

2 The financing logistics enterprise pays set proportional guarantee money to NRF-LC service platform based on the business budget. 
3 The financing logistics enterprise applies for settlement of service fees towards the NRFLC service platform, depending on the available settlement voucher.

4 The large-scale logistics enterprise applies for acceptance bills to the banks in order to pay for operational fees to the financing logistics enterprise.

5 The involved banks issue a bill to the financing logistics enterprise as their service fees.

The numeric characters in Figure 4 represent the following:

1 The NRF-LC service platform works out the customer reconciliation statement and submits it to the customers for confirmation.

2 The NRF-LC service platform reconciles service fees with the financing logistics enterprise and with the customers based on the available settlement vouchers.

3 The customers complete the accounts, and settle the accounts payable to. the platform operator's account

4 The large-scale logistics enterprise repays the loans to the financial institutions.

The implementation of the financing model can accelerate the running of capital flow in the system, but a series of problems involved in the process such as the legal aspects, the mismatch of the management system and information security needs to be tackled. In response to these possible risks, there is need for the service platform to establish a consummate risk control system, which mainly includes:

- A systematic management system, consisting of the financial risk control processes and logistics risk control processes

- Open source information systems

- Using financial spin-offs and purchasing insurance for the product to address risk.

\section{COMPARISON: FINANCING MODEL AND TRADITIONAL LOAN FINANCING}

In the developed financing model (illustrated in Figure 5), the logistics enterprise pledges the notes receivable to large-scale logistics enterprises many times during the settlement period. The latter applies for a Bank Acceptance to be used to pay for the logistics service from the former on time. This resolves the logistics enterprise's shortage of funds. Meanwhile the service platform will collect a certain amount of service charges as a reward. For loan financing, the financing logistics enterprise applies for a bank loan in the early settlement period. The company is audited by the bank for its fixed assets and these are used as collateral security against the loan. The bank provides loans and charges an agreed interest rate. 


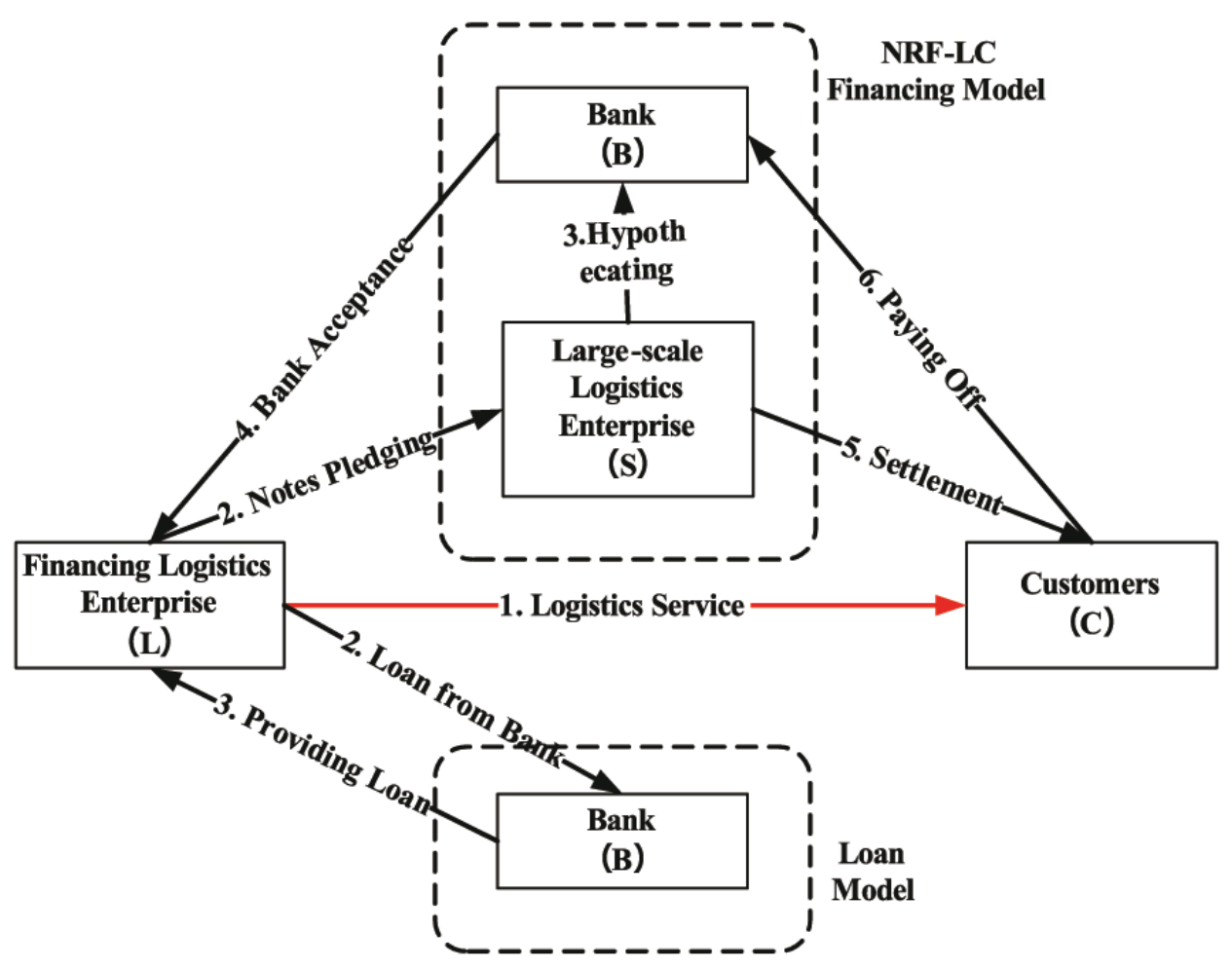

Figure 5: The logistics enterprise financing model

\section{Operation model and parameter specification}

For the financing model, the annual rate of return is represented by the symbol $\gamma$. The financial settlement cycle of customer enterprises is $T_{c}$. The total amount of the notes is $Q$. The default probability is $P_{C}$. The large-scale enterprise uses a bank acceptance (discount rate $\left.\alpha_{B}\right)$ as the tool of charge settlement and settles $N$ times for the financing logistics enterprise in the period $T_{C}$. It collects at a rate of financing service charge of $\alpha_{S}$ and charges an amount of $D_{L}$ as a deposit. The net revenue of each stakeholder is given as $I_{i}$ and the operational cost is $C_{i}^{\circ}$. In the loan financing model, the bank loan interest rate is $\beta_{B}$. The financing logistics enterprise should have fixed assets worth $A_{L}$. The repayment default probability is $P_{L}$, the net revenue of each stakeholder is $I^{\prime} \mid$ and the operation cost is $C_{i}^{\prime o}$.

\section{Revenue for the proposed financing model}

The first assumption made is as follows:

In the financing model, the large-scale logistics enterprise will settle $N$ times in time $T_{C}$, equal amounts of settlement $\mathrm{Q} / \mathrm{N}$, at a regular settlement period $T_{C} / N$.

Based on this assumption, the net revenue in the total period IL is given by:

$I_{L}=\Sigma$ (Financing Logistics Enterprise's Net Revenue per Payoff Period)

The amount paid is $Q / N$, and the actual amount acquired is $Q\left(1-\alpha_{B}-\alpha_{S}\right) / N$. The financing logistics enterprise invests the acquired settlement charge and gets a profit. The annual rate of return for the enterprise is $\gamma$, so its nominal rate of revenue in $T_{C} / N$ is $T_{c}^{\star}{ }^{*} /(365 N)$. 
The net revenue for the enterprise over a time $T_{C_{1}} L_{L}$, is calculated by using a continuous investment revenue formula, which is a function of the settlement times, $N$ :

$$
I_{L}(N)=\frac{Q}{N}\left(1-\alpha_{B}-\alpha_{S}\right)\left[\frac{\left(1+\gamma^{\prime}\right)^{N}-1}{\gamma^{\prime}}\right]
$$

Figure 6 shows the revenue analysis methodology used for the financing model compared with the traditional loan financing method.

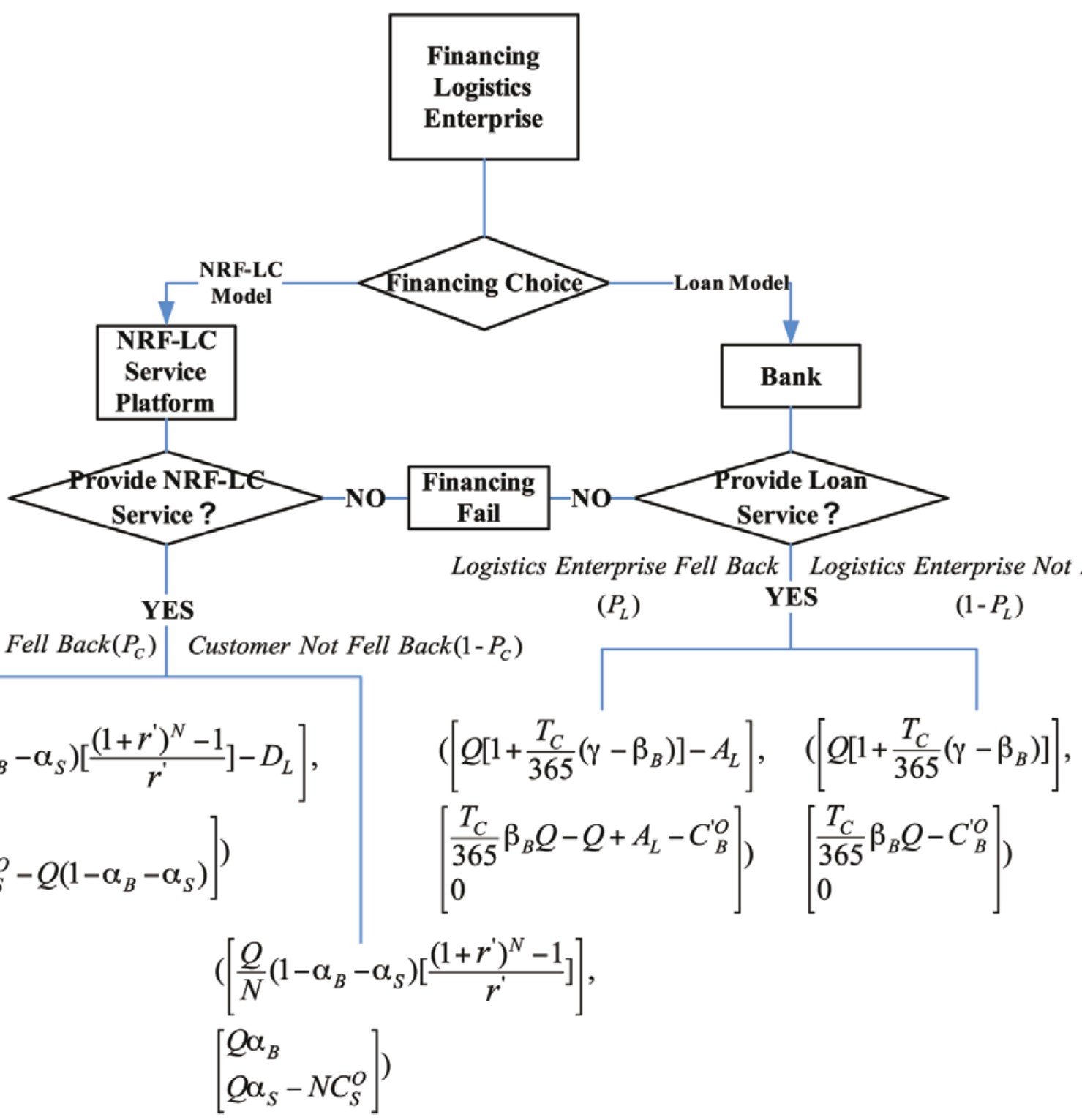

Figure 6: Revenue analysis NRF-LC model versus loan model

In the model comparison method $\gamma_{1}=\mathrm{Tc}^{*} \mathrm{r} /(365 \mathrm{~N})$, which is the nominal rate of revenue. Considering the default probability of the customer, the financing logistics enterprise may have the risk of losing the deposit, so its expected net revenue is:

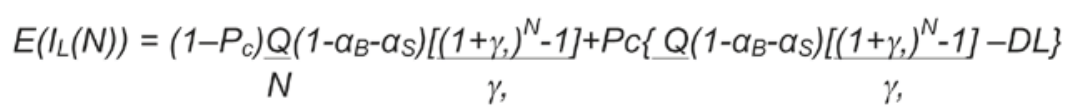


The first theorem proposed is as follows:

THEOREM 1: The expected net revenue $E\left(I_{L}(N)\right)$ of the financing logistics enterprise is the increasing function of the payment times $N$.

Considering the difficulty of getting the analytical solution of $N$, the short length of the total repayment time $T_{C}$ and the limited rate of revenue $\gamma$, we can use the simple interest formula to replace formula (3) as follows:

$$
E\left(I_{L}(N)\right)=\frac{Q}{N}\left(1-\alpha_{B}-\alpha_{S}\right)\left[N+\frac{N(N-1)}{2} \gamma^{\prime}\right]-P_{C} D_{L}
$$

\section{Revenue for the large-scale logistics enterprise}

The payment amount by the financing logistics enterprise has been indicated as $\mathrm{Q} / \mathrm{N}$ paid at regular intervals. This means that the large-scale logistics enterprise charges at a rate of $\alpha_{s} Q / N$ and the total amount in the settlement period is $\alpha_{s} Q$. At the same time, the operation cost is $C_{s}^{o}$ for every transaction and the total transaction cost is $N C_{s}^{\circ}$.

The expected net revenue of the large-scale logistics enterprise is therefore:

$$
E\left(I_{S}(N)\right)=\left[Q \alpha_{S}+P_{C} D_{L}-P_{C} Q\left(1-\alpha_{B}\right)\right]-N C_{S}^{o}
$$

\section{The bank revenue}

The financing logistics enterprise acquires $Q / N$ for every payment and for a discount rate $\alpha_{B}$ the bank collects $\alpha_{B} Q / N$ bringing the total financing service charge to $\alpha_{B} Q$. The financing risk of the bank is directly proportional to the default probability of the customer. However if the large-scale logistics enterprise is chosen after a strict audit by the bank, the default probability can be very low. The following assumption was made:

The default probability of a well screened large-scale logistics enterprise is zero, namely the financing risk of the bank is zero. (This works in China due to stiff laws.)

The third assumption made is:

In the new financing model, the bank hands the financing business over to the service provider hence the operation cost of the bank is also zero.

Based on the above assumptions, the expected net revenue of the bank is:

$$
E\left(I_{B}\right)=\left(1-P_{C}\right) Q a_{B}+P_{C} Q a_{B}=Q a_{B}
$$

\section{The revenue expected in direct loan financing}

In direct loan financing, the loan financing logistics enterprise can get a loan amount $Q$, which is invested in the logistics operations. The annual rate of revenue of the logistics enterprise is $\gamma$. The loan payment rate is $\beta_{B}$, so, in the settlement period, the nominal rates of return of both sides respectively are $\frac{T_{C}}{365} \gamma$ and $\frac{T_{C}}{365} \beta_{B}$. The net revenue of the financing
logistics enterprises in this period is:

$$
I_{L}^{\prime}=Q\left[1+\frac{T_{C}}{365}\left(\gamma-\beta_{B}\right)\right]
$$


Considering the default probability $\mathrm{PL}$, the expected net revenue is:

$$
E\left(I_{L}^{\prime}\right)=Q\left[1+\frac{T_{C}}{365}\left(\gamma-\beta_{B}\right)\right]-P_{L} A_{L}
$$

In the process of providing finance, the revenue of bank $I_{B}^{\prime}$ is mainly from the loan charges to financing enterprises, $I_{B}^{\prime}=\frac{T_{C}}{365} \beta_{B} Q$. The risk of financing is directly proportional to the default probability of the loan customers. In direct loan financing, the loan security level of the SMLEs is lower than large-scale enterprise. The default probability $P_{L}$ cannot be overlooked and the financing risk cost of the bank is $Q P_{L}$. The financing service operation cost of the bank is $C_{B}^{\prime}$. The expected net revenue of the bank in the direct loan model is therefore:

$$
E\left(I_{B}^{\prime}\right)=\frac{T_{C}}{365} \beta_{B} Q-P_{L}\left(Q-A_{L}\right)-C_{B}^{\prime O}
$$

\section{The feasible region of the financing model}

From the above revenue models, we can conclude that the revenue in the new financing model is better than for direct loan financing when the following three conditions are met:

1. Revenue condition in financing logistics enterprises: $E\left(I_{L}(N)\right) \geq E\left(I_{L}^{\prime}\right)$

The critical value: $N=\frac{1}{1-W}$, where $W=\frac{730 Q\left[\frac{T_{C}}{365}\left(\gamma-\beta_{B}\right)+\alpha_{B}+\alpha_{S}\right]-P_{L} A_{L}+P_{C} D_{L}}{T_{C} \gamma Q\left(1-\alpha_{B}-\alpha_{S}\right)}$

Set $N_{\text {Min }}=\operatorname{Max}\left(\right.$ floor $\left.\left(\frac{1}{1-W}\right), 1\right)$.

In the repayment time $T_{\mathrm{C}}$, if the number of repayments $N$ meets the condition: $N \geq N_{\operatorname{Min}^{\prime}}$ then the revenue of the financing logistics enterprises in the financing model is better than for direct loan financing, as shown in Figure 7.

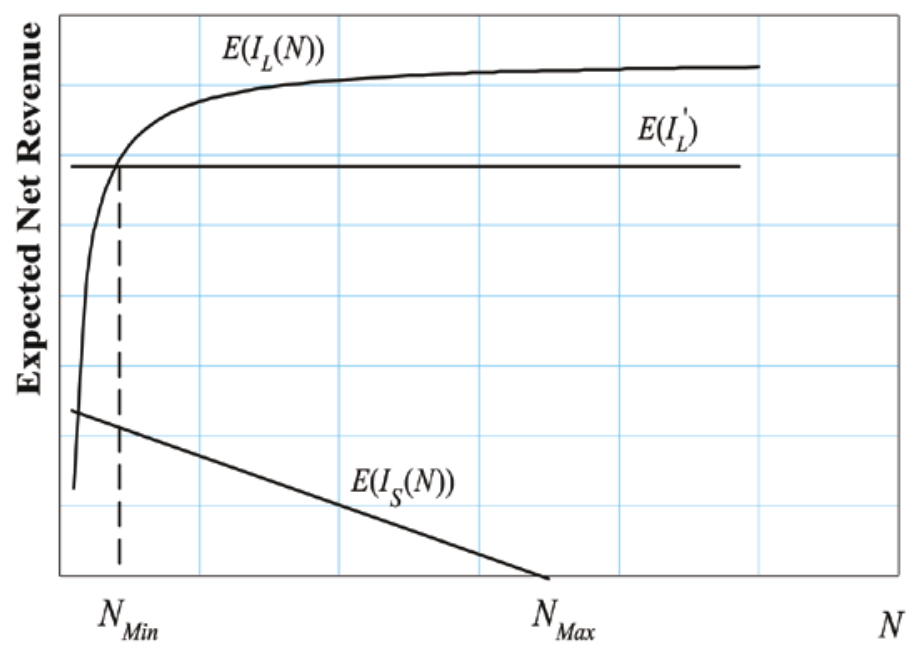

Figure 7: The expected net revenue and number of repayments $N$ relationship 
2. Revenue condition of the large-scale logistics enterprise is: $E\left(I_{S}(N)\right) \geq E\left(I_{S}^{\prime}\right)=0$

Then: $N=\frac{P_{C} D_{L}-P_{C} Q\left(1-\alpha_{B}\right)+Q \alpha_{S}}{C_{S}^{O}}$. Set $N_{\text {Max }}=\operatorname{ceil}\left(\frac{P_{C} D_{L}-P_{C} Q\left(1-\alpha_{B}\right)+Q \alpha_{S}}{C_{S}^{O}}\right)$ and $N_{\text {Max }}>N_{\text {Min }}$.

During the settlement time $T_{C}$, if the number of settlements $N$ meets the condition $N \leq N_{M a x}$, the net revenue of large-scale logistics enterprise will be more than 0 , as shown in Figure 7.

3. The revenue condition of the bank: $E\left(I_{B}\right) \geq E\left(I_{B}^{\prime}\right)$

$$
\alpha_{B}-\frac{T_{C}}{365} \beta_{B}+P_{L}>0 ; Q>\frac{P_{L} A_{L}-C_{B}^{\circ}}{\alpha_{B}-\frac{T_{C}}{365} \beta_{B}+P_{L}} ; \text { or } \alpha_{B}-\frac{T_{C}}{365} \beta_{B}+P_{L}<0, \quad Q<\frac{P_{L} A_{L}-C_{B}^{\circ}}{\alpha_{B}-\frac{T_{C}}{365} \beta_{B}+P_{L}} .
$$

If the amount financed $Q$ meets the above condition, the bank will be willing to provide the financing service. In addition to the comparison of the expected revenues, the bank should pay more attention to the default probability and the operation costs and make a detailed comparison between the three factors to determine the optimal financing service model. Therefore the feasible region of the proposed new financing model based on the summary of the above three conditions are as follows:

(A) The feasible region of the number of settlement $N$ in the new financing model is:

$F=\left\{N \mid N_{\text {Min }} \leq N \leq N_{\text {Max }}\right\}$

The financing logistics enterprise has to negotiate with the large-scale logistics enterprise for the number of settlements $N$ in the feasible region $F$ and finally agree on the number of repayments $N$ *:

$$
\begin{aligned}
N^{*} & =N_{\text {Min }}+\lambda\left(N_{\text {Max }}-N_{\text {Min }}\right) \\
& =N_{\text {Max }}-(1-\lambda)\left(N_{\text {Max }}-N_{\text {Min }}\right)
\end{aligned}
$$

In the formula $\lambda \in[0,1]$, and suggests possible bargaining power and boundaries. When $\lambda=1$, the financing logistics enterprise is in the most favourable position and can acquire maximum revenue. However, when $\lambda=0$, the result is the reverse. Putting $N$ into formulas (4) and (5), the revenues of the financing logistics and the large-scale logistics enterprise can be calculated: $E\left(I_{L}\left(N^{*}\right)\right)$ and $E\left(I_{S}\left(N^{*}\right)\right)$.

(B) The financing amount $Q$ should meet the following conditions:

$$
\alpha_{B}-\frac{T_{C}}{365} \beta_{B}+P_{L}>0, Q>\frac{P_{L} A_{L}-C_{B}^{\prime O}}{\alpha_{B}-\frac{T_{C}}{365} \beta_{B}+P_{L}} \text {, or } \alpha_{B}-\frac{T_{C}}{365} \beta_{B}+P_{L}<0, Q<\frac{P_{L} A_{L}-C_{B}^{\prime O}}{\alpha_{B}-\frac{T_{C}}{365} \beta_{B}+P_{L}}
$$




\section{Empirical analyses}

A medium-sized logistics enterprise in Shanghai provides electronic components and transportation service for a big enterprise with a monthly cost of 300000 Chinese yuan was used as a case study. The financial settlement cycle is three months and this has resulted in liquidity problems for this enterprise, stifling its daily operations and also restricting its further growth. To solve this problem, the logistics enterprise had the choice to examine two alternative financing options: the new financing model and direct loan financing. On the one hand, the financing service provider decided to provide the financing services with settlements done ten times every three months. On the other hand, a commercial bank provided direct loans for the logistics enterprise. Using the discriminatory conditions of the feasible region described earlier, the optimal financing model was chosen. The parameters involved in the case are shown in Table 1.

Table 1: Parameters of the case

\begin{tabular}{|c|c|c|c|}
\hline Parameters & Parameter's value & Parameters & Parameter's value \\
\hline$Q$ & 900000 & $D_{L}$ & 100000 \\
\hline$T_{C}$ & 90 days & $\gamma$ & $20 \%$ \\
\hline$\beta_{B}$ & 0.07 & $C_{S}^{O}$ & 300 \\
\hline$\alpha_{B}$ & 0.003 & $C_{B}^{\circ}$ & 1000 \\
\hline$\alpha_{B}$ & 0.01 & $P_{C}$ & 0.005 \\
\hline$A_{L}$ & 500000 & $P_{L}$ & 0.05 \\
\hline
\end{tabular}

(1) Revenue condition of the logistics enterprises:

The critical number of settlements, $N_{\operatorname{Min}}=\operatorname{Max}\left(\operatorname{floor}\left(\frac{1}{1-W}\right), 1\right)=4$

(2) Revenue condition of the financing service provider:

$N=\frac{P_{C} D_{L}-P_{C} Q\left(1-\alpha_{B}\right)+Q \alpha_{S}}{C_{S}^{O}}=16.71$, so $N_{\text {Max }}=\operatorname{ceil}(N)=16$

Therefore, the maximum number of settlement times that the financing service provider can accept is $N_{\text {Max }}=16$.

(3) Revenue condition of the bank:

$\alpha_{B}-\frac{T_{C}}{365} \beta_{B}+P_{L}=0.036>0$, so $Q>671521.7$

If the bank provides the financing service using the new model, the amount of money that the logistics enterprise finances should provide should be larger than 671521.7 Chinese yuan. In the case, $N=10$, which meets the condition of $N \in\left[N_{\text {Min }}, N_{\text {Max }}\right]$. Moreover, the financing amount that logistics enterprise finances is 900000 , larger than the calculated 670 000. So for this case it was recommended that the logistics enterprise should choose the new financing model. 


\section{CONCLUSIONS}

The new financing model is an innovation in logistics financing. It has been shown that it expands the logistics financing service from the property channel to the logistics channel, and puts the notes receivable into the deposit field. Through establishing the investment and finance models as proposed, studying the investment and financing strategy processes and comparing the revenues of the different stakeholders in the two models, the study determines the feasible region of the settlement times and the level of financing requirement and then analyses a case study to determine a possible optimal financing strategy. The main shortcomings are that the model works in a typically Asian culture where enterprises can fund each other. Also the interest rate regimens and fluctuations modelled are more controlled within a more command economy. Further research can consider variable and uncontrolled interest rates. Variations of the model can be considered in cases where larger enterprises guarantee rather than finance smaller enterprises. However the paper presents a more scientific and objective analysis and assessment methodology that can be used to optimise the financing of logistics operations in countries that adopt similar cultures and practices. This can be used to inform new model development and decision making in the growing field of supply chain finance. 


\section{REFERENCES}

Berger, A.N. \& Udell, G.F. 2004. A More Complete Conceptual Framework for SME Finances. Z. World Bank Report. 34: 13-121.

Buzacott, J.A. \& Zhang, R.Q. 2004. Inventory Management with Asset-based Financing. J. Management Science. 50(9): 1274-92.

China Briefing, 2011. China Issues Classification Standards for SMEs. Posted on 7 July 2011, http://www.china-briefing.com/news/2011/07/07/china-issues-classification-standards-forsmes.html (Accessed 29 February 2012).

Coulter, J. \& Onumah, G. 2002. The Role of Warehouse Receipt Systems in Enhanced Commodity Marketing and Rural Livelihoods in Africa. J. Food Policy, 27(4): 319-37.

Feng, G. 2007. Analysis of Logistics Financing Business Innovation in China. J. Forecasting, 26(01): 49-54.

Kuosmanen, T. \& Post, T. 2003. Measuring Economic Efficiency with Incomplete Price Information. J. European Journal of Operational Research. 144: 454-57.

Liu, X., Zhao, X. \& Cao, L. 2005. Optimization of A Multi-item Inventory System with Probabilistic Resource Constrains. J. Journal of Tsinghua University (Science \&Technology). 5: 714-16, 720 .

Luo, Q., Zhu, D. \& Chen, B. 2002. A Third-party Logistics Service Innovation: Financing Warehouse and Its Operation Model' J. China Business and Market. 2: 11-14.

Schwartz, E. \& Smith, J.E. 2003. Short-term Variations and Long Term Dynamics in Commodity Prices. J. Management Science. 46(7): 893-911.

Stiglitz, J.E. \& Weiss, A. 1981. Credit Rationing in Markets with Imperfect Information. J. The American Economic Review. 71(3): 393-410.

Sun, G., Chen, Q. \& Xu, H. 2006. Coordination \& decision-making between manufacturers and retailers in integrated remanufacturing \& manufacturing system. J. Computer Integrated Manufacturing Systems. 1: 127-32.

Sun, W. 2004. Business Models and Solution Architectures for SMB Financing in a Supply Chain Ecosystem of China. The Proceedings of the IEEE International Conference on E-Commerce Technology for Dynamic E-Business, 130-33. 
Zou, X. \& Tang Y. 2004. 'Logistics Financing: New Scopes of Logistics Research.' J. China Logistics and Purchasing. (17) 42-44. 